\title{
Factors Affecting in Adoption and Use of Electronic Medical Record Based on Unified Theory of Acceptance and Use of Technology in Iran
}

\author{
Mohtaram Nematollahi, ${ }^{1}$ Ahmad Moosavi, ${ }^{2}$ Mina Lazem, ${ }^{3}$ Nasim Aslani, ${ }^{3}$ Mojtaba Kafashi, ${ }^{4}$ and Ali \\ Garavand ${ }^{5, *}$ \\ ${ }^{1}$ Associate Professor, Health Information Management, Anesthesiology and Critical Care Research Center, Shiraz University of Medical Sciences, Shiraz, IR Iran \\ ${ }^{2}$ Dept. of Health and Community Medicine, Dezful University of Medical Sciences, Dezful, IR Iran \\ ${ }^{3} \mathrm{PhD}$ Student in Health Information Management, School of Health Management and Information Sciences, Iran University of Medical Sciences, Tehran, IR Iran \\ ${ }^{4}$ Department of Health Information Technology, Fasa University of Medical Sciences, Fasa, IR Iran \\ ${ }^{5} \mathrm{PhD}$ Student in Health Information Management, School of Allied Medical Sciences, Shahid Beheshti University of Medical Sciences, Tehran, IR Iran \\ "Corresponding author: Ali Garavand, PhD Student in Health Information Management, School of Allied Medical Sciences, Shahid Beheshti University of Medical Sciences, \\ Tehran, IR Iran, E-mail: virya67@yahoo.com
}

Received 2016 November 14; Revised 2017 July 04; Accepted 2017 August 08.

\begin{abstract}
Background: One of the effective factors in successful implementation of health information technology, especially electronic medical record, is investigation of adoption and its use by users. Therefore, the aim of this study was to investigate factors affecting adoption and use of electronic medical record in Shiraz teaching hospitals from the perceptive of top and middle managers.

Methods: This was a cross-sectional analytical study performed in 2015. The study population consisted of all top and middle managers $(\mathrm{N}=235$ ) of Shiraz teaching hospitals that were examined through census. Data were collected through the unified theory of acceptance and use of technology standard questionnaire. The data were analyzed using SPSS16 and LISREL8.82.

Results: The results showed that there is a direct, positive relationship between Effort Expectancy and Behavioral Intention $(\mathrm{P}=$ $0.01)$ as well as between Facilitating Condition and Behavioral Intention $(\mathrm{P}=0.04)$ and between Facilitating Condition and Use $(\mathrm{P}=$ 0.01). In addition, there was a direct, positive relationship between Behavioral Intention and Use.

Conclusions: To increase the use of Electronic Medical Record in Shiraz teaching hospitals, it is suggested that managers and policymakers consider effort expectancy and facilitating condition of this system.
\end{abstract}

Keywords: Electronic Medical Record, Unified Theory of Acceptance and Use of Technology, Hospitals, Top and Middle Managers

\section{Background}

Human of the new era is trying to accelerate the development process and apply information technology in various aspects of her/his life, away from the traditional pattern, and create a new pattern appropriate to the requirements of information era. In addition, organizations, for development and continuity of their activities, think about the promotion of health services quality and this will not be possible except through timely access to high quality information $(1,2)$.

The use of information technology in different parts of health care, especially in hospitals, provides a great potential for improving the quality of delivered services and the staff's productivity and effectiveness and causes a decrease in parts of organizational costs, as well (3). As a very important technology in health, electronic medical records have found lots of use (4).

While paper documents need thousands of dollars to be paid over the years, electronic medical records could potentially provide the return of investment during the years (5).
Electronic medical records are considered to link information of all sections and provide the information for health care providers, which is not a small task (6)

An electronic medical record (EMR) is a computerized health information system that provides detailed information such as patient demographics, encounter summaries, medical history, allergies, intolerances, and lab test histories. Some may support order entry, results management and decision support. Some may also contain features or be integrated with software that can schedule appointments, perform billing tasks, and generate reports (7).

The report of ministry of health and welfare of Japan shows that one of the elements for realizing the new healthcare information system is the electronic medical record (EMR) (8). Other studies show that both EMR and electronic health records can significantly reduce the costs of health care, increase the quality of health care services, and eventually improve the community's health status (9). Therefore, due to the importance of EMR, some programs have been developed for its adoption and use in health care industries. The American recovery and reinvestment act 
in an effort to improve the quality, increase patient satisfaction, and reduce medical errors, included $\$ 17$ billion in incentives for users of the electronic medical record system (10). However, the implementation of information technologies in health system always is faced problems and complexities (11) and these systems have been adopted by health care providers slowly (12). Therefore, we need to carry out detailed studies and investigations in this regard. One of the very important factors in the successful implementation of health information technology is the study of the acceptance and use of that technology by the users (13). In fact, measurement of the adoption rate is very helpful in successful implementation of a system, and the adoption and use of theories of information technology are very important to predict the end users' reaction to health information technology (14). However, with the growing demand for EMR, evaluating the role of the factors affecting adoption is a critical step toward defining success or failure of EMR initiatives (15). In recent decades, different models have been proposed about the adoption and use of technology among which we can mention technology acceptance model (TAM), unified theory of acceptance and use of technology (UTAUT), theory of reasoned action (TRA), diffusion of innovation (DOI), and so on. These theories discuss the issue of the adoption of new technologies on social systems (16). Thereupon in recent years, many studies have been done in the context of the adoption and use of electronic medical records. Nevertheless, among the proposed theories, the unified theory of acceptance and use of technology (UTAUT) as one of the newest proposed theories integrates the other theories and finally up to 70\% can indicate the people's intention to use information systems (17). This theory helps the managers assess the likelihood of acceptance of a new technology within an organization. It also helps in understanding factors that drive acceptance of a new technology (18). This model was proposed by Venkatesh et al. that includes performance expectancy, effort expectancy, social influence, and facilitating conditions, as independent variables, behavioral intention as independent and dependent variable, and the use as dependent variable. It finally shows the impact of independent variables on the dependent variable i.e. the acceptance and use of technology (17). Jason et al. in a study entitled "south African physicians' acceptance of e-prescribing technology: an empirical test of a modified UTAUT model" concluded that the facilitating conditions have the most important influence on the acceptance of e-prescribing; also, the cost and the social influence had the lowest effect on the use of acceptance of e-prescribing by physicians (19). In a study entitled "Using the UTAUT Model to Explore Iranian Physicians and Nurses' Intention to Adopt Electronic Patient Records" conducted by Hamidfar et al. the relationship between the parameters of UTAUT and behavioral intention was investigated among 113 physicians and nurses of Toos, Shariaty, and Dey hospitals of Tehran city by using a questionnaire. In this study, two factors named facilitating conditions and personal innovation were added to the main factors of the model and their influence was investigated. The results showed the positive effect of the constructs of this model on technology adoption by the research community that these factors included performance expectancy, effort expectancy, social factors, and facilitating conditions (20). In addition, the obtained results showed that the variance of the use intention explained by the final model was $76.8 \%$ (20). Because of the importance of managers' decisions in hospitals and staff performance, we selected them as subjects in our study. The aim of the present study was to determine effective factors in adoption and use of the useful technology, i.e. electronic medical record, based on the UTAUT from the viewpoint of top and middle managers in the teaching hospitals of Shiraz.

\section{Methods}

This cross-sectional analytical study was done in 2015. The study population comprised top and middle managers of all teaching hospitals in Shiraz that included 14 hospitals. Due to the limitation of the research population, sampling was not performed and based on census, all of the 235 top and middle managers were included in the study. From the 235 distributed questionnaires, 121 questionnaires were finally collected. Therefore, the response rate to the questionnaires was $52 \%$. Data collection tool was the standard questionnaire of UTAUT model that its content validity was evaluated with the opinion of five academic members of health information management and information technology departments of Shiraz University of Medical Sciences. Then, the questions of the questionnaire were determined and for measuring the reliability, the questionnaire was administered to a sample of 20 persons other than research sample. The reliability of the questionnaire was calculated as 0.71 by Cronbach's Alpha statistical test. The questionnaire consisted of two parts as follows: demographic data (age, gender, work experience, educational level) and questions related to the UTAUT model that included performance expectancy (questions 1 to 4), effort expectancy (questions 5 to 7), social influence (questions 8 to 12), facilitating condition (questions 13 to 17), intention of the use (questions 18 to 20), and use (questions 21 to 25). Questions related to the model were scored on the same scale based on the Likert scale from 1 to 5 that respectively corresponded from very low to very high. Data were analyzed using LISREL 8.80 statistical software to determine the fit of the model and SPSS 17 to calculate de- 
scriptive statistics (analysis of demographic data) and analytical statistics (Pearson correlation coefficient, regression, independent t-test, and ANOVA). Six hypotheses according to Figure 1, one hypothesis about the impact of demographic variables on study variables, and one hypothesis about determining the fitness of the used model, which totally comprised 8 hypotheses, were investigated.

To determine the quality of the fit of the model using LISREL software, the report of the following indices is enough (21-23).

Inclusion criteria to the study included being a top or middle manager in teaching hospitals of Shiraz. Data collection was done consciously with getting necessary consents. All respondents were assured that the information would remain confidential until the end of the study.

\section{Results}

The results showed that $73 \%$ of the respondents were female and the rest were male. $31 \%$ aged above 40 years. In terms of education, $4.1 \%$ had associate degree, 65.3\% had bachelor's degree, and the rest were MSc, PhD, or specialist.

Table 1 shows the relationship between the demographic variables and latent variables in this study. In the most cases, the relationship between variables was not significant $(P$ value $=0.05)$.

Table 1. Investigation of the Relationship Between Age, Sex, Degree, and Latent Variables

\begin{tabular}{lccc}
\hline Tests & $\begin{array}{c}\text { Age } \\
\text { ANOV(A P } \\
\text { Value) }\end{array}$ & $\begin{array}{c}\text { Degree } \\
\text { ANOVA(A P } \\
\text { Value) }\end{array}$ & $\begin{array}{c}\text { Sex } \\
\text { Independent } \\
\text { Sample t- Test } \\
\text { (A P Value) }\end{array}$ \\
\hline $\begin{array}{l}\text { Performance } \\
\text { Expectancy }\end{array}$ & 0.3 & 0.4 & 0.2 \\
\hline $\begin{array}{l}\text { Effort } \\
\text { Expectancy }\end{array}$ & 0.2 & 0.8 & 0.3 \\
\hline $\begin{array}{l}\text { Social } \\
\text { Influence }\end{array}$ & 0.8 & 0.4 & 0.1 \\
\hline $\begin{array}{l}\text { Facilitating } \\
\text { Condition }\end{array}$ & 0.3 & 0.5 & 0.06 \\
\hline $\begin{array}{l}\text { Behavioral } \\
\text { Intention }\end{array}$ & 0.1 & 0.04 & 0.4 \\
\hline \begin{tabular}{l} 
Use \\
\hline
\end{tabular} & 0.2 & 0.03 & 0.7 \\
\hline
\end{tabular}

According to Table 1, degree is the only effective factor in Behavioral Intention and Use.

The UTAUT model was investigated in Table 2.

According to Table 2, there is no significant relationship between Performance Expectancy and Behavioral Intention $(P$ value $=0.29)$. According to Table 3 , each three accepted relationships based on P-values have a direct, positive relationship based on $\mathrm{R}$ and $\mathrm{R} 2$.

The values of the RMSEA, CFI, GFI, AGFI, NFI, NNFI, and $\mathrm{x}^{2} / \mathrm{df}$ indices show that the model's fit is appropriate (Table 4).

According to Table 4, based on the calculated fit indices, the UTAUT model well showed the factors affecting adoption and use of Electronic Medical Record.

\section{Discussion}

In fact, with growth of needs to digital information in health care, the EMR has been recognized as one of the main factors in Information Technology, and with growth of requests for assessment of EMR, the role of its Use Possibility takes a vital step to define the Success or failure of it (15). Therefore, many studies will be done in the context of factors affecting adoption and use of it.

The results of the present study showed that the demographic variables (age, gender, and degree) have no effect on the adoption and use of EMR. Nematollahi et al. (24) achieved the same results in their study.

The results of the present study showed that there is no significant relationship between performance expectancy and behavioral intention, which is inconsistent with the results of the Khorasani et al.'s study (25). This may be due to the poor familiarity of the top and middle managers with the usefulness of the electronic medical records or extra work that the existing computer systems have created in hospitals (documents scanning, printing of the typing reports, etc.). In fact, their low efficiency led the top and middle managers not to pay attention to their efficiency in the use intention of electronic medical records.

Other results of this study showed that there is a significant relationship between Effort Expectancy and Behavioral Intention. This means that the effort of a person to learn how to work with the technology has a specific effect on the use intention of that technology. The result of this study is consistent with the results of Wills et al. (15) and Mailleta et al. studies (26).

In addition, there was no significant relationship between Social Influence and Behavioral Intention. Although, the result of Jason et al.'s study (19) is consistent with the results of our study, the result of this part of the study is not consistent with those of the Wills et al. (15) and Holtz and Krein's studies (27). Although, most of the previous studies signify the relationship between social influences and use intention of technology, this study shows that there is no significant relationship between these two factors. This means that the others' opinion about the importance of using the electronic medical record has no effect on the use intention of it by the top and middle man- 


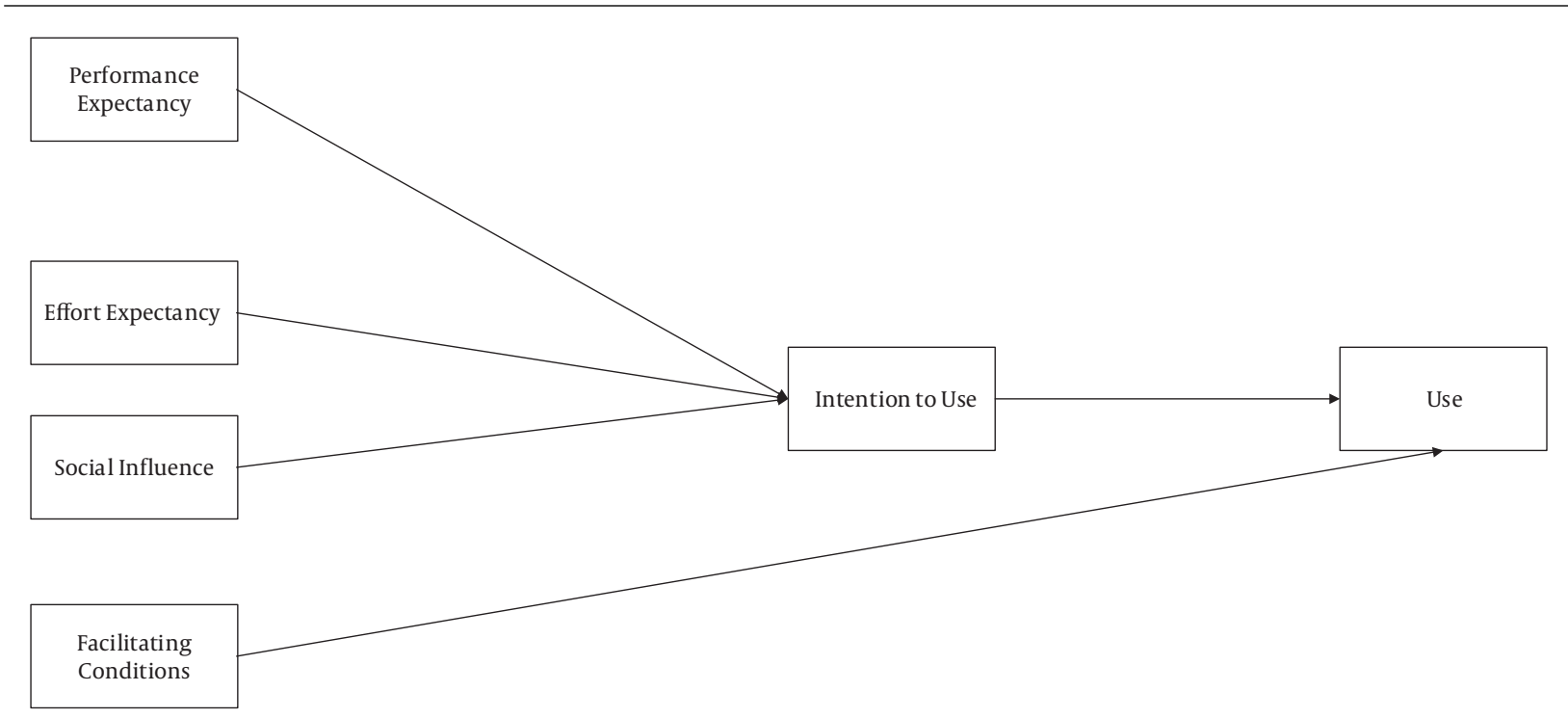

Figure 1. Unified Theory of Acceptance and Use of Technology (UTAUT)

Table 2. The Investigation of the Relationship Between Independent and Dependent Variables Based on P Value

\begin{tabular}{|c|c|c|c|c|}
\hline \multirow{3}{*}{$\begin{array}{l}\text { Variables } \\
\text { Performance Expectancy }\end{array}$} & \multirow{2}{*}{\multicolumn{2}{|c|}{$\begin{array}{c}\text { Behavioral Intention } \\
\text { PValue }\end{array}$}} & \multirow{2}{*}{\multicolumn{2}{|c|}{$\begin{array}{c}\text { Use } \\
\text { P Value }\end{array}$}} \\
\hline & & & & \\
\hline & 0.29 & $*$ & - & - \\
\hline Effort Expectancy & 0.01 & $\sqrt{ }$ & - & - \\
\hline Social Influence & 0.36 & $*$ & - & - \\
\hline Facilitating Condition & 0.04 & $\sqrt{ }$ & 0.01 & $\sqrt{ }$ \\
\hline Behavioral Intention & - & - & 0.01 & * \\
\hline
\end{tabular}

${ }^{\mathrm{a}}$ The check mark $(\sqrt{ })$ means the acceptance of the relationship, and the star mark $\left({ }^{*}\right)$ means the rejection of the existing relationship.

Table 3. The Type of Relationship in the Accepted Hypotheses

\begin{tabular}{|c|c|c|c|c|}
\hline & \multicolumn{2}{|c|}{ Behavioral Intention } & \multicolumn{2}{|c|}{ Use } \\
\hline & $\mathbf{R}$ & $\mathbf{R}^{2}$ & $\mathbf{R}$ & $\mathbf{R}^{2}$ \\
\hline Effort Expectancy & 0.22 & 0.05 & - & - \\
\hline Facilitating Condition & 0.18 & 0.03 & 0.22 & 0.04 \\
\hline Behavioral Intention & - & - & 0.01 & 0.13 \\
\hline
\end{tabular}

agers. It seems that holding briefing workshops is necessary to inform the top and middle managers about the importance of their staff's attitude about the use intention and the use of electronic medical records for its successful implementation to pay more attention to the effect of social influences on intention use of it.

Other results of this study showed that there is a significant relationship between Facilitating Condition and Be- havioral Intention. Wills et al. (15), Hamidfar et al. (20), and Aggelidis et al. (28) achieved the same results. This means that top and middle managers of hospitals should pay attention to the conditions and factors that facilitate the use of electronic medical record. Facilitating Conditions play an important role in the use intention of electronic medical records, which is the tendency of an individual to try to do the desired work or behavior. Therefore, by improving 
Table 4. Fit Indices of the Model

\begin{tabular}{lcc}
\hline Index & Calculated Value & Fit Status \\
\hline RMSEA & 0.07 & $\sqrt{ }$ \\
X2/df & 1.60 & $\sqrt{ }$ \\
\hline CFI & 0.95 & $\sqrt{ }$ \\
\hline NFI & 0.90 & $\sqrt{ }$ \\
\hline NNFI & 0.94 & $\sqrt{ }$ \\
GFI & 0.81 & $\sqrt{ }$ \\
\hline AGFI & 0.80 & $\sqrt{ }$ \\
\hline
\end{tabular}

the existing resources such as computers and other hardware devices, increasing the related knowledge, training specialists in information technology and health information management and their accessibility for personnel associated with electronic medical records we can facilitate its use intention.

The results showed that there is a significant relationship between Facilitating Condition and Use. This part of the study is in line with the previous part of the study, i.e. the relationship between Facilitating Condition and Behavioral Intention.

In addition, there was a significant relationship between Behavioral Intention and Use, which is consistent with the results of many studies such as those of Aggelidis et al. (28), Wills et al. (15), and Holtz and Krein (27).

In fact, the researchers concluded in their studies that the use intention of a technology (individual's tendency to try to do the desired behavior or work) leads to the actual use of it. Investigating and understanding factors affecting the use intention of electronic medical records can lead to the actual use of this system. It seems that the use intention is the main factor affecting the use of technology, because in many models such as TAM and UTAUT, this factor is mentioned as the main and direct factor affecting the adoption or actual use of the technology. In addition, the present study showed that the UTAUT has an appropriate fit that can be used to assess factors affecting the adoption and use of electronic medical records.

\subsection{Conclusions}

The researchers by using these models in their studies have facilitated the implementation of health information technology. It seems that due to the need of teaching hospitals of Shiraz for implementation of the electronic medical record and regarding the results of this study, we can increase the acceptance rate and use of it by holding training courses for top and middle managers and acquaint them with the benefits of electronic medical records, creating the motivation in managers, introducing it as a key tool in health care services delivery, and paying attention to facilitating factors such as financial and scientific supports and effective knowledge. These eventually will lead to the successful implementation of the EMR. In addition, it is suggested for the researchers and authorities to implement other information technologies by employing the technology acceptance theories especially UTAUT.

\section{Acknowledgments}

This study was a part of a research project No. 937156, which has been done with financial support of the research vice chancellor of Shiraz University of Medical Sciences. In addition, researchers express their gratitude to all top and middle managers who participated in completing the questionnaires.

\section{References}

1. Barzegar R. From electronic learning to mobile learning: theoretical principles. Interdisciplinar JVirtual Learn Med Sci. 2012;3(2):35-41.

2. Sittig DF, Singh H. Defining health information technology-related errors: new developments since to err is human. Arch Intern Med. 2011;171(14):1281-4. doi: 10.1001/archinternmed.2011.327. [PubMed: 21788544].

3. Price A. A study of factors influencing physician adoption of electronic medical records technology. Grenoble Ecole de Manag. 2010.

4. Chae YM, Yoo KB, Kim ES, Chae H. The adoption of electronic medical records and decision support systems in Korea. Healthc Inform Res. 2011;17(3):172-7. doi: 10.4258/hir.2011.17.3.172. [PubMed: 22084812].

5. Block BM. How we improved our practice and our bottom line with a new EMR system. Fam Pract Manag. 2008;15(7):25-30. [PubMed: 18763681].

6. Carter JH. Electronic medical records: a guide for clinicians and administrators. ACP Press; 2001.

7. Ludwick DA, Doucette J. Adopting electronic medical records in primary care: lessons learned from health information systems implementation experience in seven countries. Int J Med Inform. 2009;78(1):22-31. doi: 10.1016/j.ijmedinf.2008.06.005. [PubMed: 18644745].

8. Toyoda K. Standardization and security for the EMR. Int J Med Inform. 1998;48(1-3):57-60. [PubMed: 9600404].

9. Follen M, Castaneda R, Mikelson M, Johnson D, Wilson A, Higuchi K. Implementing health information technology to improve the process of health care delivery: a case study. Dis Manag. 2007;10(4):20815. doi: 10.1089/dis.2007.104706. [PubMed: 17718659].

10. Schenarts PJ, Schenarts KD. Educational impact of the electronic medical record. J Surg Educ. 2012;69(1):105-12. doi: 10.1016/j.jsurg.2011.10.008. [PubMed: 22208841].

11. Lluch $M$. Healthcare professionals' organisational barriers to health information technologies-a literature review. Int J Med Inform. 2011;80(12):849-62. doi: 10.1016/j.ijmedinf.2011.09.005. [PubMed: 22000677].

12. Chau PYK, Hu PJH. Information Technology Acceptance by Individual Professionals: A Model Comparison Approach. Decision Sci. 2001;32(4):699-719. doi: 10.1111/j.1540-5915.2001.tb00978.x.

13. Kijsanayotin B, Pannarunothai S, Speedie SM. Factors influencing health information technology adoption in Thailand's community health centers: applying the UTAUT model. Int J Med Inform. 
2009;78(6):404-16. doi: 10.1016/j.jimedinf.2008.12.005. [PubMed: 19196548].

14. Holden RJ, Karsh BT. The technology acceptance model: its past and its future in health care. J Biomed Inform. 2010;43(1):159-72. doi: 10.1016/j.jbi.2009.07.002. [PubMed: 19615467].

15. Wills MJ, El-Gayar OF, Bennett D. Examining healthcare professionals' acceptance of electronic medical records using UTAUT. Issues Inf Systems. 2008;9(2):396-401.

16. Liu SH, Liao HL, Peng CJ. Applying the technology acceptance model and flow theory to online e-learning users' acceptance behavior. $E$ learn. 2005;4(H6):H8.

17. Venkatesh V, Morris MG, Davis GB, Davis FD. User acceptance of information technology: Toward a unified view. MIS Q. 2003:425-78.

18. Gupta B, Dasgupta S, Gupta A. Adoption of ICT in a government organization in a developing country: An empirical study.J Strateg Inf Systems. 2008;17(2):140-54. doi: 10.1016/j.jsis.2007.12.004.

19. Cohen JF, Bancilhon JM, Jones M. South African physicians' acceptance of e-prescribing technology: An empirical test of a modified UTAUT model. South Afr Comput J. 2013;50(1):43-54.

20. Azoulay E, Mokart D, Rabbat A, Pene F, Kouatchet A, Bruneel F, et al. Diagnostic bronchoscopy in hematology and oncology patients with acute respiratory failure: prospective multicenter data. Crit Care Med. 2008;36(1):100-7. doi: 10.1097/01.CCM.0000295590.33145.C4. [PubMed: 18090351].

21. Payandeh A, Omidi M. Confirmatory Structured Analysis. Tehran:
Shahid Beheshti University publication; 2013.

22. James LR, Mulaik SA, Brett JM. Causal analysis: Assumptions, models, and data. 1. SAGE Publications, Incorporated; 1982.

23. Mulaik SA, James LR, Van Alstine J, Bennett N, Lind S, Stilwell CD. Evaluation of goodness-of-fit indices for structural equation models. Psychol Bull. 1989;105(3):430-45. doi: 10.1037/0033-2909.105.3.430.

24. Nematollahi M, Garavand A, Monem H. Factors Affecting the Intention to Use Electronic Medical Records from the Perspective of Top and Middle Managers of Shiraz Teaching Hospitals.J Health Biomed Inf. 2015;2(1):1-7.

25. Khorasani A, Abdolmaleki J, Zahedi H. Factors affecting E-Learning acceptance among students of tehran university of medical sciences based on technology acceptance model (TAM). Iran J Med Educ. 2012;11(6):664-73.

26. Maillet E, Mathieu L, Sicotte C. Modeling factors explaining the acceptance, actual use and satisfaction of nurses using an Electronic Patient Record in acute care settings: an extension of the UTAUT. Int J Med Inform. 2015;84(1):36-47. doi: 10.1016/j.ijmedinf.2014.09.004. [PubMed: 25288192].

27. Holtz B, Krein S. Understanding Nurse Perceptions of a Newly Implemented Electronic Medical Record System. J Technol Human Serv. 2011;29(4):247-62. doi: 10.1080/15228835.2011.639931.

28. Aggelidis VP, Chatzoglou PD. Using a modified technology acceptance model in hospitals. Int J Med Inform. 2009;78(2):115-26. doi: 10.1016/j.ijmedinf.2008.06.006. [PubMed: 18675583]. 